\title{
Alteration of smoking habit at time of first diagnosis influences survival of patients with HNSCC
}

\author{
ASITA FAZEL $^{1 *}$, ELGAR SUSANNE QUABIUS $^{1,2^{*}}$, MIREIA GONZALES-DONATE $^{1}$, \\ MARTIN LAUDIEN $^{1}$, ARVED HERZOG ${ }^{1}$, KONSTANTIN KRESS ${ }^{1}$, THILO SCHLEICHER ${ }^{1}$, \\ ALEXANDER FABIAN $^{3}$, KAREN HUBER $^{3}$ and MARKUS HOFFMANN ${ }^{1}$ \\ ${ }^{1}$ Department of Otorhinolaryngology, Head and Neck Surgery; ${ }^{2}$ Institute of Immunology; ${ }^{3}$ Department of Radiooncology, \\ Christian-Albrechts-University, University Hospital Schleswig-Holstein, D-24105 Kiel, Germany
}

Received October 8, 2019; Accepted June 2, 2020

DOI: $10.3892 / \mathrm{mco} .2020 .2120$

\begin{abstract}
The impact of smoking on survival in patients with squamous cell carcinoma of the head and neck is well established, despite some conflicting data in the literature. However, data on alterations of smoking habit following cancer diagnosis is sparse. In the present study, the effect of reduction of smoking compared with cessation on the course of disease was studied. Data from 643 patients with HNSCC from the tumor documentation registry of the Department of Otorhinolaryngology, Head and Neck Surgery of the Christian-Albrechts-University Kiel were collected and statistically analyzed, looking at pre- and post-treatment smoking habit and survival. Alteration of smoking at the first diagnosis of HNSCC led to a significantly beneficial effect on survival outcomes compared with continued smoking, without significant differences between reduction and cessation of smoking. Detailed analysis revealed that this effect was solely dependent on patients treated by surgery only. Lifelong non-smokers exhibited a significant survival advantage compared with active and former smokers, with no difference in survival between these last two groups. The positive influence of altered smoking habit following first time diagnosis on disease-specific survival paralleled the negative direct effect of active smoking on therapy, which is predominantly attributed to peritumoral tissue hypoxia leading to impaired efficacy of radiochemotherapy (RCT). In the present study cohort, the positive effect of smoking habit alterations were primarily observed in patients treated by surgery only instead
\end{abstract}

Correspondence to: Professor Markus Hoffmann, Department of Otorhinolaryngology, Head and Neck Surgery, Christian-AlbrechtsUniversity, University Hospital Schleswig-Holstein, Building 27, Campus Kiel, Arnold-Heller-Strasse 3, D-24105 Kiel, Germany

E-mail: markus.hoffmann@uksh.de

*Contributed equally

Key words: smoking cessation, smoking reduction, head and neck cancer, squamous cell carcinoma of the head and neck, survival of RCT, possibly due to fewer perioperative complications. These findings indicated that patients should be encouraged to at least minimize smoking following cancer diagnosis. Furthermore, for survival estimates and therapy planning, former smokers should be considered as active smokers.

\section{Introduction}

There are two predominant factors influencing the carcinogenesis and survival of patients with squamous cell carcinoma (SCC) of the head and neck (HNSCC): i) Infection with human papillomavirus (HPV); and ii) the burden of tobacco and alcohol consumption (1-3). HPV accounts for a substantial proportion of SCCs, specifically of the tonsils (oropharynx), with a positive impact on survival $(1,2)$, whereas the components found in tobacco smoke and alcohol are associated with the genesis of laryngeal and hypopharyngeal SCC (3). Although there are some conflicting data (4-6), it is widely accepted that smoking has a significant negative effect on the survival of patients with $\operatorname{HNSCC}(1,2)$. There have been various primarily retrospective studies into the course of disease of smokers in comparison to former smokers and lifelong non-smokers, with additional focus on pre- and post-treatment smoking habit of patients in some of these studies (4-9). The majority of studies analyzing patients' smoking habit prior to diagnosis describe a clear survival advantage of non-smoking, followed by ex-smoking and then active smokers (7-9). Studies which focus on pre- and post-treatment smoking habit describe an improved course of disease for patients who quit smoking $(8,9)$. In case of treatment with primary or adjuvant radiochemotherapy (RCT), the latter is primarily associated with peritumoral tissue hypoxia-related incomplete response to RT (10), along with no response to platinum-based induction CT (11). In case of treatment by surgery only, the positive effect of smoking cessation at the time of diagnosis is attributed to improved wound healing, fewer complications such as pneumonia and a decrease in second primary malignancies (12).

In a large population-based study, Sharp et al (9) reported for the first time that the positive effect of quitting can predominantly be recognized in the group of patients that are treated by surgery only, whereas survival data of patients who ceased or continued smoking whilst receiving any form of RCT 
were more or less indistinguishable. In Europe, and Germany in particular, the proportion of smokers in the population with cancer is higher than in countries with more successful anti-smoking campaigns (13), and surgery as single treatment option, even in oropharyngeal SCC, plays a more pronounced role in Europe when compared with the US.

Due to these findings, the effects of pre- and post-treatment smoking habit were analyzed, with additional stratification for treatment regimes. Moreover, it was investigated as to whether the positive effects of alterations to smoking habit at the time of first diagnosis can only be observed in the case of complete smoking cessation, or whether smoking reduction may have similar positive effects. The latter is encouraged, as a substantial proportion of active smokers are more likely to successfully achieve a reduction in rather than quit smoking.

\section{Patients and methods}

Study design. The files of 643 patients with HNSCC, treated between 2013 and 2016 at the Department of Otorhinolaryngology, Head and Neck Surgery of the Christian-Albrechts-University Kiel (Kiel, Germany) were retrospectively analyzed.

The main dependent variables were overall survival (OS) and disease-specific survival (DSS), with a follow-up range of 0.01-4.4 years and mean follow-up of 1.62 years. The independent variable was smoking status, assessed either prior to or after diagnosis. In addition, altered smoking after diagnosis was investigated for separate treatment groups. Smoking habit prior to diagnosis was classified as either 'never smoked', 'active smoker' or 'former smoker', when patients stopped smoking at least 2 years prior to diagnosis. Smoking habit after diagnosis was classified as 'no change' (patients are still active smokers), 'reduced' (tobacco consumption was reduced to $<10$ cigarettes per day) and quit (patients stopped their tobacco consumption completely).

To increase numbers, patients treated by primary or adjuvant RT or RCT were pooled and compared to patients treated by surgery only. At the department of the study, the optimal target dose for primary and adjuvant RCT is $300 \mathrm{mg}$ cisplatin or carboplatin per $\mathrm{m}^{2}$ body surface area. Usually, $100 \mathrm{mg} / \mathrm{m}^{2}$ were administered at week 1, 3, and 5. Target doses for radiation are: 70 gy for primary RT and 60 gy for adjuvant RT. Mortality was censored on 1st October, 2017.

Outcome variables. The main outcomes were OS and DSS. Survival was defined as either the time in years from date of diagnosis until date of death from any cause (OS), or as the time in years to primary tumor-related death (DSS).

Statistical analysis. Kaplan-Meier plots and log-rank tests (SPSS 20.0; IBM Corp.) were used to compare independent variables and mortality. To analyze statistical differences between different subgroups, pairwise log-rank comparisons with Bonferroni correction were additionally performed. In addition, Cox univariate analysis (forward stepwise; SPSS 20.0) was performed to analyze survival advantages dependent on smoking habit alone or in combination with patient treatment regimes. One-way ANOVA was performed to assess age-related differences between active, never and former smokers, whereas Student's t-test was performed to assess age-related differences between patients that reduced or stopped tobacco consumption after diagnosis (both SPSS 20.0). $\mathrm{P} \leq 0.05$ was considered to indicate a statistically significant difference.

\section{Results}

Patient demographics. Patient characteristics $(n=643)$ are described in Table I. The mean age was $64.5 \pm 10.2$ years (range, 39.86-98.02 years). The majority of patients were male [77.3\% (497/643)]. Prior to diagnosis, 349 patients $(54.4 \%)$ reported a smoking habit (active smokers), $113(17.6 \%)$ reported having never smoked and 180 (28.0\%) reported to have quit smoking at least 2 years prior to diagnosis (former smokers). No information regarding smoking status was available for 1 patient treated by surgery only. Of those patients reporting to be active smokers at time of diagnosis, $50(14.3 \%)$ stopped smoking after diagnosis and 38 (10.9\%) reduced their tobacco consumption to $<10$ cigarettes per day. While patients reporting to be active smokers prior to diagnosis were significantly younger than never or former smokers (never smoked, 68.6 \pm 10.9 ; former smokers, 68.4 \pm 9.7 ; active smokers, $61.0 \pm 8.5 ; \mathrm{P}<0.001)$, no age-related difference was observed between those patients who continued smoking after diagnosis and those who quit or reduced their tobacco consumption ( $\mathrm{P}>0.05$; data not shown). Anatomical tumor sites were as follows: Oral cavity, $\mathrm{n}=51(7.9 \%)$; hypopharynx, $\mathrm{n}=94(14.6 \%)$; larynx, $\mathrm{n}=163(25.3 \%)$; tonsil, $\mathrm{n}=95(14.8 \%)$; oropharynx other than tonsil, $\mathrm{n}=155(24.1 \%)$; nasopharynx, $\mathrm{n}=49(7.6 \%)$ and other sites, $\mathrm{n}=36(5.6 \%)$. Patients were treated as follows: i) The majority of patients were treated by surgery only (315 patients; $49.0 \%)$; ii) 111 patients $(17.3 \%$ ) were treated by primary RCT; iii) 24 patients $(3.7 \%)$ received primary RT; iv) 121 patients $(18.8 \%)$ were treated by adjuvant RCT; and v) 72 patients $(11.2 \%)$ were treated by adjuvant RT. For further statistical analysis, all patients treated by either primary RCT or RT, or by adjuvant RCT or RT were pooled, resulting in a total of 328 patients treated by $\mathrm{R}(\mathrm{C}) \mathrm{T}$; of these, 137 patients were treated with cisplatin, but data regarding the cisplatin dosage were available for only 115 cases, rendering further survival analysis in the present context impossible. Of all $328 \mathrm{R}(\mathrm{C}) \mathrm{T}$ patients, 62 were never smokers, 89 were former smokers and 177 were active smokers, of which 16 reduced and 21 quit tobacco consumption after diagnosis. Similarly, of the 315 patients treated by surgery, only 51 had never smoked, with 91 former smokers and 172 active smokers, of which 22 reduced and 29 quit their tobacco consumption after diagnosis. For 1 further patient, no information regarding smoking habit was available.

Kaplan-Meier analysis of OS and DSS. The 3-year OS and DSS rates were $78.2 \%(111 / 142)$ and $80.6 \%$ (70/87), respectively. The detailed results of the Kaplan-Meier analysis for OS and DSS, together with the 3-year survival rates are shown in Table II. Patients who stopped tobacco consumption at least 2 years prior to diagnosis had no significant survival advantage when compared with active smokers $(\mathrm{P}=0.165$ and $\mathrm{P}=0.105$ for OS and DSS, respectively). In Fig. 1, the survival curves of all patients separated by smoking habit are shown. The 
Table I. Patient characteristics.

\begin{tabular}{|c|c|c|}
\hline Variables & No & $\begin{array}{c}\text { Percentage } \\
(\%)\end{array}$ \\
\hline \multicolumn{3}{|l|}{ Sex } \\
\hline Female & 146 & 22.7 \\
\hline Male & 497 & 77.3 \\
\hline \multicolumn{3}{|l|}{ Smoking habit prior to diagnosis } \\
\hline Never smoked & 113 & 17.6 \\
\hline Former smoker $^{\mathrm{a}}$ & 180 & 28.0 \\
\hline Active smoker & 349 & 54.4 \\
\hline \multicolumn{3}{|c|}{ Altered smoking habit after diagnosis } \\
\hline Cessation & 50 & 14.3 \\
\hline Reduction $^{\mathrm{b}}$ & 38 & 10.9 \\
\hline Continued smoking & 261 & 74.8 \\
\hline \multicolumn{3}{|l|}{ Status (as of 1st October 2017) } \\
\hline Alive & 501 & 77.9 \\
\hline Dead & 142 & 22.1 \\
\hline \multicolumn{3}{|l|}{ Cause of death } \\
\hline Primary tumor & 87 & 61.3 \\
\hline Secondary tumor & 6 & 4.2 \\
\hline Not tumor related & 23 & 16.2 \\
\hline Unclear & 26 & 18.3 \\
\hline \multicolumn{3}{|l|}{ Tumor site } \\
\hline Oral cavity & 51 & 7.9 \\
\hline Hypopharynx & 94 & 14.6 \\
\hline Larynx & 163 & 25.3 \\
\hline Tonsil & 95 & 14.8 \\
\hline Oropharynx other than tonsil & 155 & 24.1 \\
\hline Nasopharynx & 49 & 7.6 \\
\hline Other & 36 & 5.6 \\
\hline \multicolumn{3}{|l|}{ Therapy } \\
\hline Surgery only & 315 & 49.0 \\
\hline Primary RCT & 111 & 17.3 \\
\hline Primary RT & 24 & 3.7 \\
\hline Adjuvant RCT & 121 & 18.8 \\
\hline Adjuvant RT & 72 & 11.2 \\
\hline
\end{tabular}

aPatients quit smoking at least 2 years prior to diagnosis; ${ }^{\text {PPatients }}$ reduced their tobacco consumption after diagnosis to $<10$ cigarettes per day. RCT, radiochemotherapy; RT, radiotherapy.

results demonstrated a survival advantage for never smoking ( $\mathrm{P}=0.002$ for $\mathrm{OS}$ and $\mathrm{P}=0.005$ for $\mathrm{DSS}$ ), with no significant improvement in outcome for former smokers $(\mathrm{P}=0.157$ for $\mathrm{OS}$ and $\mathrm{P}=0.105$ for DSS vs. active smokers). Further pairwise log-rank tests demonstrated significantly improved OS for never smokers compared with active $(\mathrm{P}<0.001)$ and former smokers $(\mathrm{P}=0.014)$, as well as significantly improved DSS ( $\mathrm{P}=0.002$ and $\mathrm{P}=0.041$, respectively; Fig. $1 \mathrm{~A}$ and $\mathrm{B}$ ).

Patients who either reduced tobacco consumption $<10$ cigarettes per day [(38/349), 10.9\%] or quit [(50/349), $14.3 \%]$ tobacco consumption after first tumor diagnosis had significantly improved OS and DSS compared with patients who continued smoking $(\mathrm{P}=0.05$ and $\mathrm{P}=0.045$ for $\mathrm{OS}$ and DSS, respectively; Table II): The 3-year OS rates were 75.0 and $77.0 \%$ for patients who reduced or quit smoking, respectively, compared with $61.6 \%$ in patients who continued smoking; 3 years DSS rates were 89.7 and $85.9 \%$ for patients who reduced or quit smoking, respectively, compared with $72.8 \%$ in patients who continued smoking (Table II). In Fig. 2A and B, these results are shown as Kaplan-Meier curves, including the survival curves of the patients who never smoked, demonstrating a clear survival benefit for the never smokers (86.1\% OS and 89.8\% DSS), with an overall $\mathrm{P}=0.002$ for OS and $\mathrm{P}=0.001$ for DSS. Pairwise log-rank comparisons (stated in detail in the Fig. 2 legend) revealed significant differences in OS for never smokers compared with continued smokers $(\mathrm{P}<0.001)$ and those that reduced their smoking $(\mathrm{P}=0.047)$, but not those that quite smoking $(\mathrm{P}=0.111)$. There were no significant differences in OS for patients that reduced tobacco consumption compared with active smokers $(\mathrm{P}=0.347)$ or those that quit smoking $(\mathrm{P}=0.347)$; however, patients who quit smoking exhibited significantly different OS compared with active smokers $(\mathrm{P}=0.049)$. In DSS, significant differences were only observed between never smokers and active smokers $(\mathrm{P}<0.001)$, and active smokers and those that quit smoking $(\mathrm{P}=0.047)$.

When stratifying the effect of continued tobacco consumption, quitting, and/or reduction in relation to patient treatment, log-rank tests for patients treated by surgery only analyzing DSS $(\mathrm{P}=0.045)$ and $\mathrm{OS}(\mathrm{P}=0.05)$ demonstrated a significant survival advantage for patients who reduced or quit tobacco consumption after diagnosis (Table II). Including the survival data of the never-smoking patients treated by surgery only into the equation demonstrated a survival advantage for these patients (overall $\mathrm{P}=0.017$ for $\mathrm{OS} ; \mathrm{P}=0.005$ for DSS; Fig. 2C and D). Pairwise comparisons of the survival data of patients treated by surgery only again revealed significant differences in OS between never smokers and active smokers $(\mathrm{P}=0.003)$, and active smokers and patients that quit smoking $(\mathrm{P}=0.049)$. For DSS, pairwise comparisons revealed significant differences when active smokers were compared with never smokers $(\mathrm{P}=0.004)$, patients that quit smoking $(\mathrm{P}=0.035)$ and patients that reduced their smoking $(\mathrm{P}=0.045)$. In patients treated by RCT, altered smoking habit at time of diagnosis had no significant effect on OS $(\mathrm{P}=0.664)$ or $\mathrm{DSS}(\mathrm{P}=0.588)$. Including the survival data of the patients that never smoked into the equation did also not reveal a significant effect of smoking habit on survival $(\mathrm{P}=0.11$ for $\mathrm{OS} ; \mathrm{P}=0.195$ for $\mathrm{DSS}$; Fig. 2E and F).

Cox univariate analysis of $O S$ and $D S S$ in relation to smoking habit. To further analyze the effects of smoking habit before or after cancer diagnosis, Cox univariate analysis was performed. The results are shown in Table III, corroborating the results obtained by Kaplan-Meier analysis. The data demonstrated that OS and DSS was, when compared with never smokers, significantly worse in active $(\mathrm{P}=0.001$ for OS; $\mathrm{P}=0.021$ for $\mathrm{DSS})$ and former smokers $(\mathrm{P}=0.017$ for OS; $\mathrm{P}=0.041$ for DSS), with no significant difference between active and former smokers ( $\mathrm{P}=0.253$ for $\mathrm{OS} ; \mathrm{P}=0.159$ for $\mathrm{DSS}$; Table III). Patients who either reduced or quit their tobacco consumption exhibited worse OS when compared with never 


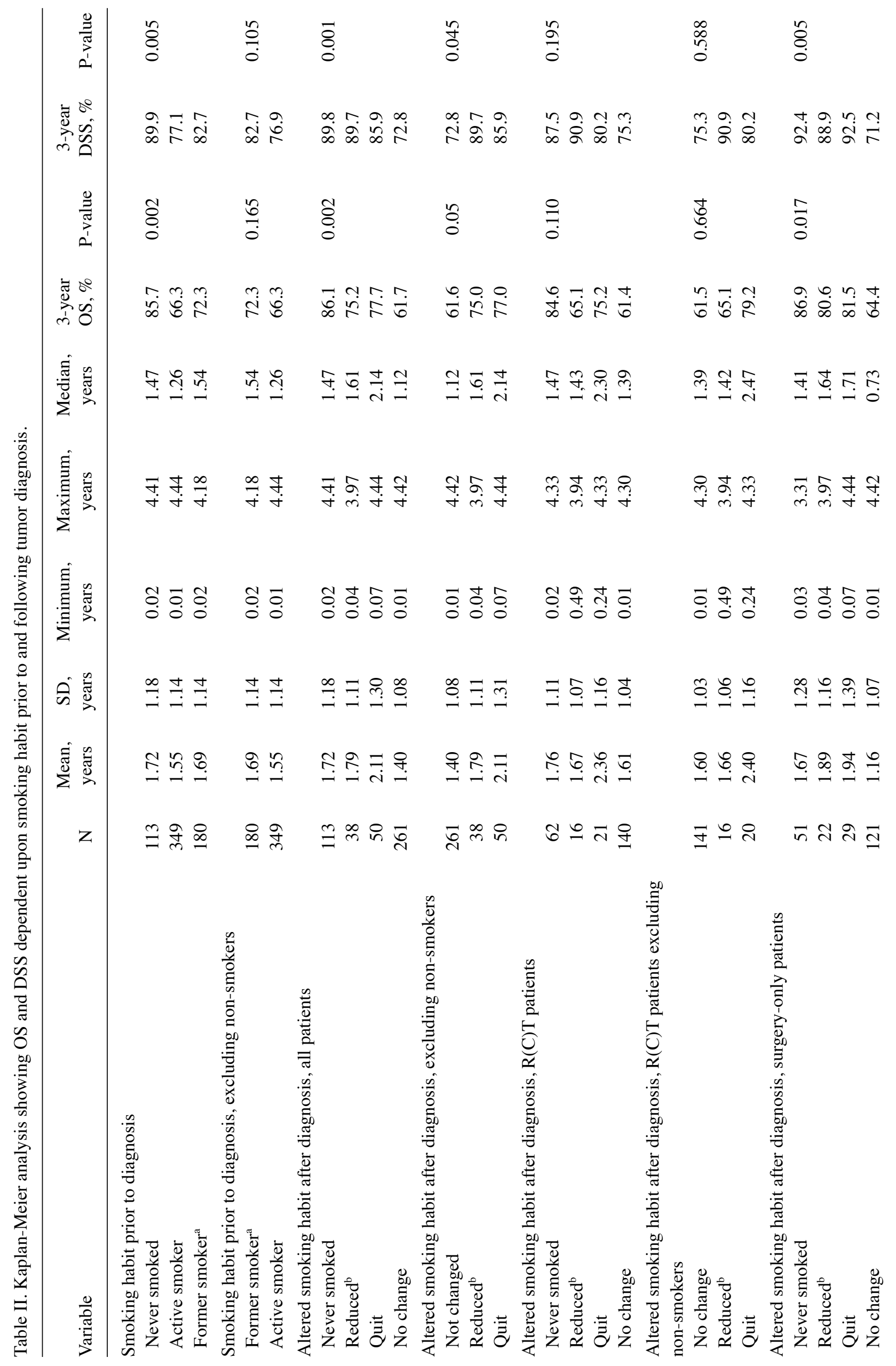




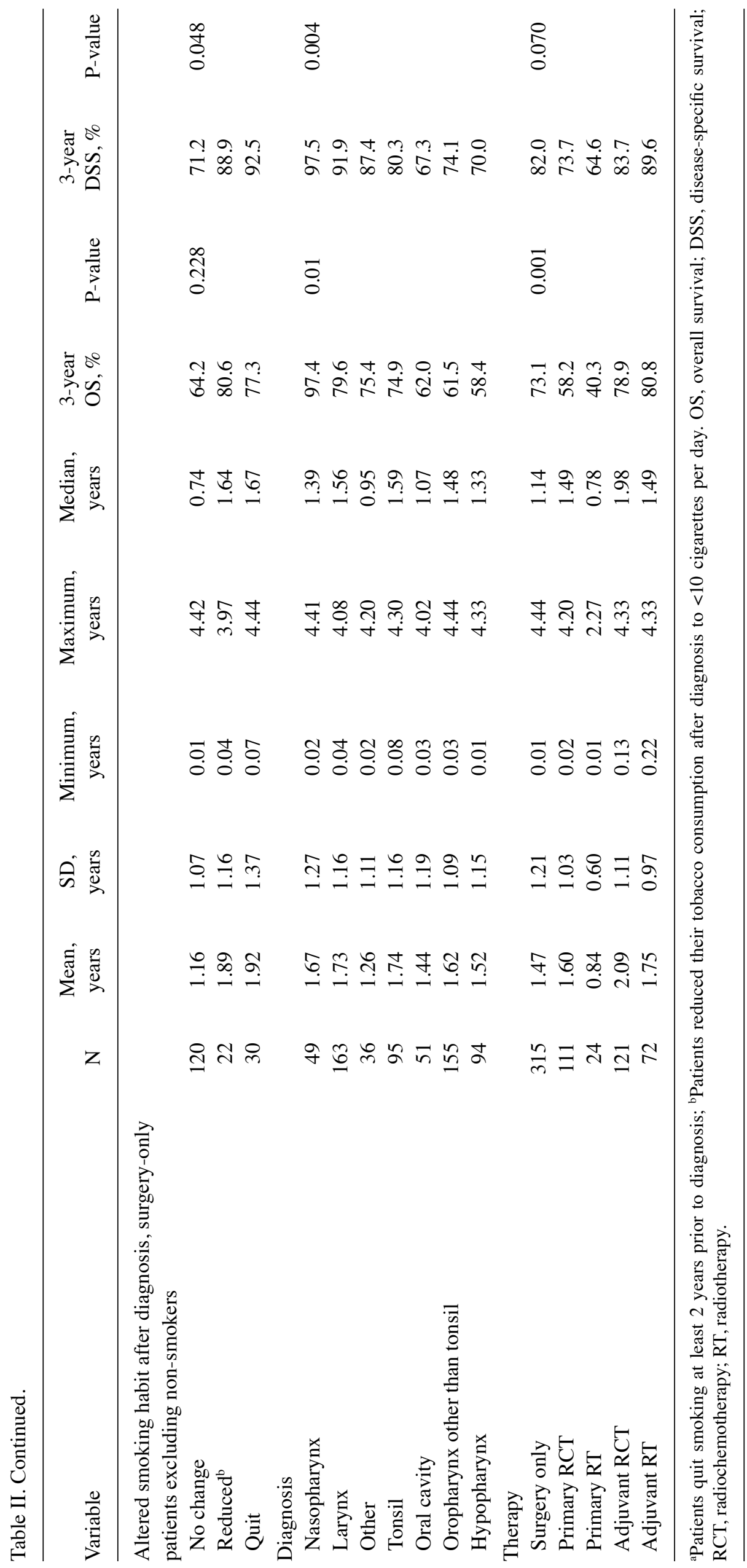



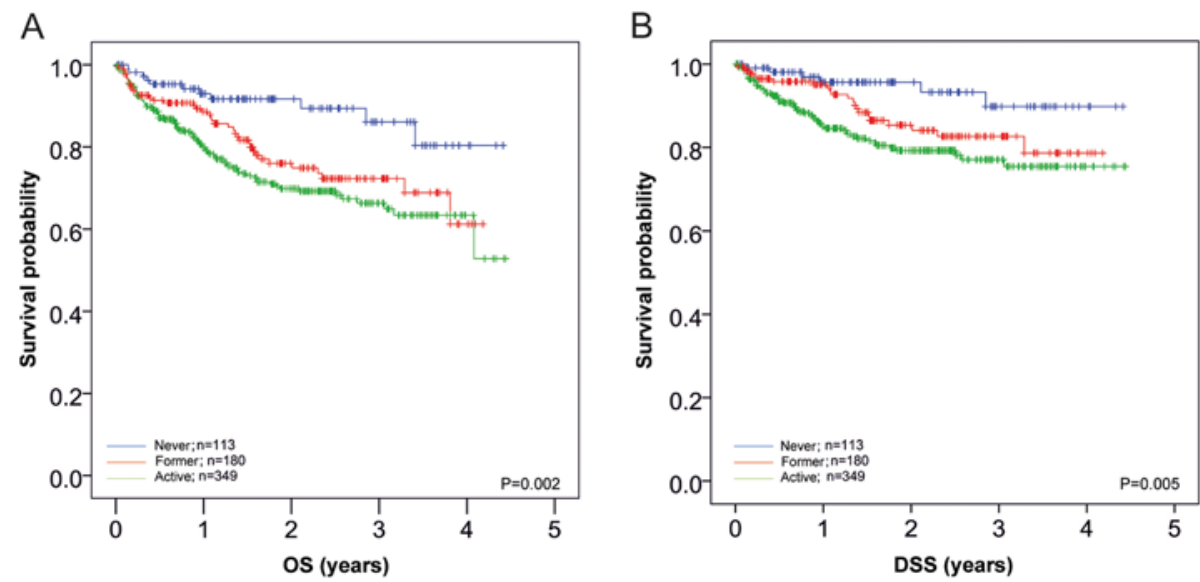

Figure 1. Effects of smoking habit prior to diagnosis on OS and DSS of patients with HNSCC. (A) OS and (B) DSS of patients with HNSCC in relation to smoking habit were analyzed. OS in patients that never smoked ( $\mathrm{n}=113$; blue line), former smokers ( $\mathrm{n}=180$; red line) and active smokers ( $\mathrm{n}=349$; green line) was 85.7, 72.3 and $66.3 \%$ after 3 years, respectively. The data indicated a significant $(\mathrm{P}=0.002)$ effect of smoking on survival; however, no significant difference was observed between former smokers and active smokers ( $\mathrm{P}=0.157)$. DSS in non-smokers, former smokers and active smokers was $89.9,82.7$ and $77.1 \%$ after 3 years; a significant $(\mathrm{P}=0.005)$ effect of smoking status on DSS was found. However, no significant difference was observed between former and active smokers $(\mathrm{P}=0.105)$. Further pairwise log-rank tests revealed significant differences in OS between patients that never smoked compared with active $(\mathrm{P}<0.001)$ and former smokers $(\mathrm{P}=0.014)$, with similar differences in DSS $(\mathrm{P}=0.002$ and $\mathrm{P}=0.041$, respectively). OS, overall survival; DSS, disease-specific survival; HNSCC, squamous cell carcinoma of the head and neck.

smokers $(\mathrm{P}=0.016$ and $\mathrm{P}=0.04$ for smoking reduction and smoking cessation, respectively, vs. never smokers), whereas active smokers exhibited the worst $\mathrm{OS}(\mathrm{P}<0.001$ vs. never smoked; Table III and Fig. 2A). Similar results were obtained in patients treated by surgery only $(\mathrm{P}=0.035$ and $\mathrm{P}=0.045$ for smoking reduction and smoking cessation, respectively, vs. never smoked). Furthermore, when comparing active smokers with patients that never smoked, OS was significantly worse $(\mathrm{P}<0.001$; Table III and Fig. 2C). In patients treated by $\mathrm{R}(\mathrm{C}) \mathrm{T}$, OS was not affected by the smoking habit of the patients; none of the former or active smokers had significantly different survival rates compared with the never smokers $(\mathrm{P}=0.055$ for smoking reduction, $\mathrm{P}=0.079$ for quitting, $\mathrm{P}=0.051$ for patients who continued smoking; Table III and Fig. 2E).

Analysis of DSS in all patients showed that reduction or cessation of tobacco consumption shifted the survival rates towards the survival rates of the never smokers $(\mathrm{P}=0.995$ for reduction vs. never smoked; $\mathrm{P}=0.155$ for quitting); patients who did not change their smoking habit had the worst DSS ( $\mathrm{P}=0.001$; Table III and Fig. 2B). Similar results were obtained in patients treated by surgery only. Again, no significant differences were seen between patients who never smoked compared with those who reduced their tobacco consumption $(\mathrm{P}=0.134)$ or quit smoking completely $(\mathrm{P}=0.146)$. Patients who continued smoking again had the worst outcome $(\mathrm{P}=0.001$; Table III and Fig. 2D). In $R(C) T$ patients, however, no such differences were found $(\mathrm{P}=0.751, \mathrm{P}=0.321$ and $\mathrm{P}=0.061$ for reduction, quitting and continued smoking, respectively, vs. never smoked).

Hence, the positive effects of reducing or quitting smoking for OS and DSS observed in the entire cohort were based on the favorable outcomes of patients treated with surgery only.

\section{Discussion}

In light of the present literature, there were three results of specific interest observed by analyzing 643 patients with
HNSCC for the impact of smoking habit on survival in a single center setting: i) Patients who quit smoking at least 2 years before cancer diagnosis/treatment did not exhibit survival rates that differed from those of active smokers; ii) reduction of smoking at the time of cancer diagnosis led to comparable, albeit slightly inferior, positive effects on survival rates when compared with quitting smoking; and iii) this was specifically observed in the group of patients treated with surgery only. These data were in accordance with the findings reported by Sharp et al (9). Rather expected was the finding that smoking (active or past) was detrimental to OS and DSS for all patient groups regardless of treatment. These data were consistent with various other studies into the issue $(1,2,14)$.

The majority of studies into smoking habit and cancer describe the survival rates of former smokers to be intermediate compared with active smokers (lower survival rate) and those that never smoked (improved survival) $(8,9,15,16)$. In the present study, however, there were no significant differences in survival between former and active smokers for DSS or OS. Only one study could be identified showing comparable data (17). One hypothesis explaining these data would be that a person who quits smoking at least 2 years prior to a cancer diagnosis has a decreasing risk of developing cancer over time; however, once this person does suffer from HNSCC, there is no survival benefit when compared to a person that continued to smoke. These results appear to somewhat contradict the other findings from the present study that indicated positive survival effects for patients who quit or reduced smoking following first diagnosis and before treatment. However, the two described effects of smoking history could be based on different mechanisms: While quitting smoking following first time diagnosis may have direct, most likely hypoxia-related positive effects on post-operative wound healing and peri-operative complication rates (12), both of which will improve survival outcome, the negative long-term effects of extended tobacco smoke exposure may be linked to genetic 

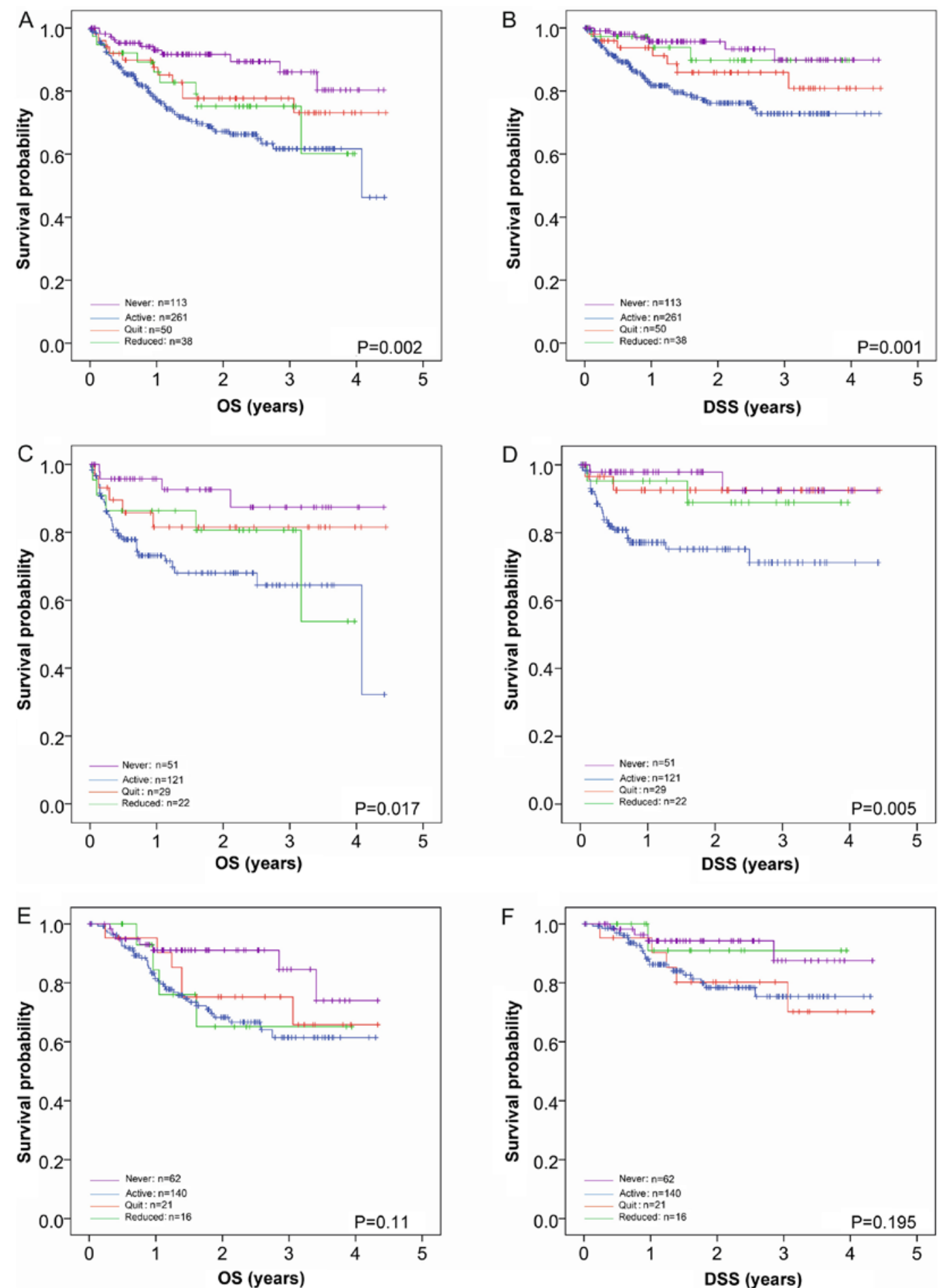

Figure 2. Effects of altered smoking habit at time of diagnosis on OS and DSS in patients with HNSCC. (A) OS and (B) DSS of patients with HNSCC irrespective of treatment is shown $(\mathrm{n}=462)$. Patients who continued smoking (blue line; $\mathrm{n}=261)$ exhibited the worst 3 -year OS $(61.7 \%)$ and DSS $(72.8 \%)$, whereas never smokers ( $\mathrm{n}=113$; magenta line) exhibit the highest survival ( 86.1 and $89.8 \%$, respectively). Those that reduced $(\mathrm{n}=38$; green line) and quit smoking ( $\mathrm{n}=50$; red line) exhibited intermediate survival rates. The effects of smoking habit post-diagnosis on OS ( $\mathrm{P}=0.002)$ and $\mathrm{DSS}$ ( $\mathrm{P}=0.001)$ were significant. Pairwise comparisons revealed significant differences in OS for never smokers compared with continued smokers $(\mathrm{P}<0.001)$ and those that reduced their smoking $(\mathrm{P}=0.047)$, but not those that quite smoking $(\mathrm{P}=0.111)$. There were no significant differences in OS for patients that reduced tobacco consumption compared with active smokers $(\mathrm{P}=0.347)$ or those that quit smoking $(\mathrm{P}=0.347)$; however, patients who quit smoking exhibited significantly different $\mathrm{OS}$ compared with active smokers $(\mathrm{P}=0.049)$. Pairwise comparisons revealed significant differences in DSS only between never smokers and active smokers $(\mathrm{P}<0.001)$, and active smokers and those that quit smoking ( $\mathrm{P}=0.047)$. (C) OS and (D) DSS of patients treated with surgery only $(\mathrm{n}=223)$. Smoking habit significantly influenced OS $(\mathrm{P}=0.017)$ and DSS $(\mathrm{P}=0.005)$ in patients treated with surgery only. Pairwise comparisons revealed significant differences in OS between never smokers and active smokers $(\mathrm{P}=0.003)$, and active smokers and patients that quit smoking $(\mathrm{P}=0.049)$. Pairwise comparisons revealed significant differences in $\mathrm{DSS}$ when active smokers were compared with never smokers $(\mathrm{P}=0.004)$, patients that quit smoking $(\mathrm{P}=0.035)$ and patients that reduced their smoking $(\mathrm{P}=0.045)$. $(\mathrm{E}) \mathrm{OS}$ and $(\mathrm{F})$ DSS of patients treated by $\mathrm{R}(\mathrm{C}) \mathrm{T}(\mathrm{n}=239)$. There were no significant effects of smoking habit observed on OS $(\mathrm{P}=0.11)$ or $\mathrm{DSS}(\mathrm{P}=0.195)$ in patients treated with R(C)T. The 3-year OS of the never smokers, active smokers, reduced smokers and those that quit were 84.6, 61.4, 65.1 and 75.2\%, respectively. The 3-year DSS of the never smokers, active smokers, reduced smokers and those that quit were 87.5, 75.3,90.9 and 80.2\%, respectively. In all plots, former smokers (those that quit smoking $>2$ years prior to diagnosis) were excluded. OS, overall survival; DSS, disease-specific survival; HNSCC, squamous cell carcinoma of the head and neck; $\mathrm{R}(\mathrm{C}) \mathrm{T}$, radio(chemo)therapy. 
Table III. Univariate Cox analysis for OS and DSS.

\begin{tabular}{|c|c|c|c|c|c|c|}
\hline \multirow[b]{2}{*}{ Variables } & \multicolumn{3}{|c|}{ OS } & \multicolumn{3}{|c|}{ DSS } \\
\hline & $\mathrm{HR}$ & $95 \% \mathrm{CI}$ & P-value & HR & $95 \% \mathrm{CI}$ & P-value \\
\hline \multicolumn{7}{|c|}{ Smoking habit prior to diagnosis vs. never smoked } \\
\hline Active smoker & 1.669 & $0.882-3.159$ & 0.001 & 1.805 & $1.073-3.185$ & 0.021 \\
\hline Former smoker & 1.192 & $0.493-2.883$ & 0.017 & 1.431 & $1.165-3.209$ & 0.041 \\
\hline \multicolumn{7}{|c|}{ Smoking habit prior to diagnosis vs. former smoker } \\
\hline Active smoker & 1.495 & $0.916-2.440$ & 0.253 & 1.309 & $0.900-1.904$ & 0.159 \\
\hline \multicolumn{7}{|c|}{$\begin{array}{l}\text { Altered smoking habit after diagnosis vs. never smoked, } \\
\text { all patients }\end{array}$} \\
\hline Reduced $^{\mathrm{b}}$ & 2.990 & $1.224-7.307$ & 0.016 & 1.063 & $0.151-4.364$ & 0.955 \\
\hline Quit & 2.435 & $1.041-5.694$ & 0.040 & 1.328 & $0.842-6.697$ & 0.155 \\
\hline No change & 4.522 & $2.343-8.728$ & $<0.001$ & 4.766 & $1.843-12.178$ & 0.001 \\
\hline \multicolumn{7}{|c|}{$\begin{array}{l}\text { Altered smoking habit after diagnosis vs. never smoked, } \\
\text { patients treated by surgery only }\end{array}$} \\
\hline Reduced $^{\mathrm{b}}$ & 2.705 & $0.725-10.087$ & 0.035 & 1.011 & $0.243-14.983$ & 0.134 \\
\hline Quit & 1.967 & $0.527-7.330$ & 0.045 & 1.521 & $0.245-11.030$ & 0.146 \\
\hline No change & 4.141 & $0.470-11.721$ & 0.001 & 6.279 & $0.431-25.954$ & 0.001 \\
\hline \multicolumn{7}{|c|}{$\begin{array}{l}\text { Altered smoking habit after diagnosis vs. never smoked, } \\
\text { patients treated by } \mathrm{R}(\mathrm{C}) \mathrm{T}\end{array}$} \\
\hline Reduced $^{b}$ & 2.299 & $0.572-7.857$ & 0.055 & 1.276 & $0.323-9.265$ & 0.751 \\
\hline Quit & 1.942 & $0.651-5.709$ & 0.079 & 2.217 & $0.836-7.615$ & 0.321 \\
\hline No change & 2.585 & $1.154-5.792$ & 0.051 & 2.698 & $0.539-10.165$ & 0.061 \\
\hline
\end{tabular}

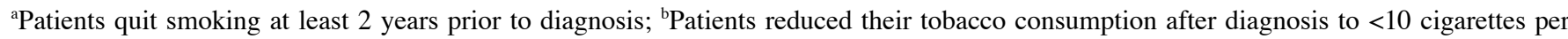
day. Survival analysis based on smoking status is presented for the overall cohort, as well as specific treatment groups. OS, overall survival; DSS, disease-specific survival; RCT, radiochemotherapy; RT, radiotherapy.

aberrations (18) and smoking-associated co-morbidity $(16,17)$, leading to impaired survival outcomes. In fact, in the present study, smokers who quit or reduced smoking at first time diagnosis exhibited improved survival rates compared with ex-smokers, with 3-year OS rates of 76.7 and $72.3 \%$ (DSS, 87.5 and $82.6 \%$ ), respectively; however, the reason for this remains unclear.

The improved survival of patients who reduced or quit smoking at time of first cancer diagnosis, which was observed across the entire study cohort, was specifically observed in the group of patients that were treated with surgery only. Thus, the present analysis validated the findings reported by Sharp et al (9). This is noteworthy, as the evidence in the literature is not unanimous, with various studies reporting effects of smoking habit on survival outcomes only when: i) Treatment regimens included radiotherapy; ii) the tumors were HPV-negative; and iii) $\mathrm{p} 16^{\mathrm{INK} 4 \mathrm{~A}}$ status in immunohistochemistry was additionally stratified for $(14,19,20)$, whereas others did not see an association between smoking habit and survival under any circumstances $(4,5)$. In the present study, neither HPV nor p16 $6^{\mathrm{INK} 4 \mathrm{~A}}$ status were included in the analysis, as all patients were treated prior to the routine inclusion of these parameters into patient check-ups. A review and meta-analysis by Grønkjær et al (12) summarized that pre-operative smoking increased the risk of wound complications, general infections, pulmonary infections, neurologic complications and admission to intensive care units. The data from the present study suggested that treatment-related and smoking-dependent co-morbidities might be responsible for the impact of smoking on the OS and DSS of patients with HNSCC. Moreover, the data reported in the present study and by Sharp et al (9) contradict the frequently stated assumption that smoking compromises outcomes predominantly among those treated with radiation therapy by decreasing oxygenation and/or reducing the effects of radiation-induced tumor killing (7). The lack of consensus in this matter becomes more evident when considering that Browman et al (10) published a landmark article suggesting that active smoking during radiation therapy was detrimental with respect to OS, progression-free survival and complication-free survival; a subsequent follow-up study the same authors conducted, however, did not corroborate these findings (21).

As previously described, positive effects on survival have been found for patients quitting smoking before or at the time of cancer diagnosis (9). To the best of our knowledge, the present study is the first showing that a reduction in smoking ( $<10$ cigarettes per day) leads to a beneficial effect on patient survival. This may be an encouraging finding, as it is more likely for patients to achieve a reduction in smoking than to quit smoking altogether, particularly at times of mental distress 
due to a cancer diagnosis (8). In Germany and other European Countries, it is well established that the proportion of smokers among the general population is substantially higher than in the USA, which has more successful anti-smoking campaigns (10). Our recent study reported that the proportion of smokers among patients with HPV-negative and HPV-positive tonsillar SCC is 70 and $50 \%$, respectively (2). Thus, clinicians could be encouraged to recommend at least a reduction of tobacco consumption at first visit. According to the present data, to reduce or quit smoking should be recommended to all patients that will receive treatment for HNSCC, and this holds true whether or not the treatment regimens include $\mathrm{R}(\mathrm{C}) \mathrm{T}$. Of note, only $56 \%$ of physicians recommend to their cancer patients who smoke that they stop smoking, and most oncology providers do not provide smoking interventions beyond advice to quit (8). In this context, it is noteworthy that requirements for head and neck oncology certificates formulated by the German Cancer Society, for example, include, among other points, psycho-oncologic and nutrition care, as well as other concomitant support, but no offers for cessation interventions. Evidence in the literature strongly advocates changing this and implementing such interventions in the care of patients with cancer.

Limitations of this analysis are primarily based on the retrospective nature of the study. This means that certain specific questions remain unanswered due to a lack of precise documentation in the patient's files. One of these questions is whether or not the patients that reduced or quit smoking at the time of cancer diagnosis actually maintained the alterations in smoking habit, as in follow-up examinations, smoking status is not routinely questioned. Similarly, it cannot be fully excluded that patients considered as former smokers did not relapse after cancer diagnosis due to the intense mental distress. It has been estimated that $\sim 50 \%$ of patients with cancer who smoked prior to diagnosis fail to stop smoking or relapse after diagnosis (8). In the case that a substantial proportion of smokers not only failed to quit or reduce smoking but relapsed to former smoking habit from prior to the cancer diagnosis, the survival benefits of quitting or reducing smoking may be underestimated in the present study.

In conclusion, the findings of the present study support encouraging patients to alter their smoking habit, even if this only entails reducing tobacco consumption, regardless of which treatment regimen is planned. Smoking cessation interventions must be integrated into the holistic care of patients with cancer. Future efforts are required to clarify which factors exactly are responsible for the survival advantages observed in the subgroup of patients treated with surgery only who reduced or stopped their tobacco consumption following their cancer diagnosis. Clinicians should be motivated to support smoking cessation among their patients.

\section{Acknowledgements}

The authors thank Dr Crystal Moore (Environmental Agency, United Kingdom) for careful and critical reading of the manuscript.

\section{Funding}

No funding was received.

\section{Availability of data and materials}

The datasets used and/or analyzed during the current study are available from the corresponding author on reasonable request.

\section{Authors' contributions}

The study was conceived and designed by MH, ESQ and KH. Data were acquired by TS, KK, ALF, AH and MGD, statistically analyzed by ESQ and MH, and interpreted by ASF, ML and $\mathrm{MH}$. The manuscript was prepared by AsF, ESQ and $\mathrm{MH}$, and edited by $\mathrm{AlF}, \mathrm{KH}$ and $\mathrm{AH}$. All authors read and approved the final manuscript.

\section{Ethics approval and consent to participate}

Patients provided written informed consent to participate in the study. The study was approved by the Ethics Committee of the Medical Faculty of the Christian-Albrechts-University of Kiel (Kiel, Germany) (permit no. D 507/17).

\section{Patient consent for publication}

Not applicable.

\section{Competing interests}

The authors declare that they have no competing interests.

\section{References}

1. Ang KK, Harris J, Wheeler R, Weber R, Rosenthal DI, Nguyen-Tân PF, Westra WH, Chung CH, Jordan RC, Lu C, et al: Human papillomavirus and survival of patients with oropharyngeal cancer. N Engl J Med 363: 24-35, 2010.

2. Hoffmann M, Quabius ES, Tribius S, Gebhardt S, Görögh T, Hedderich J, Huber K, Dunst J and Ambrosch P: Influence of HPV-status on survival of patients with tonsillar carcinomas (TSCC) treated by $\mathrm{CO}_{2}$-laser surgery plus risk adapted therapy-a 10 year retrospective single centre study. Cancer Lett 413: 59-68, 2018.

3. Marur S and Forastier AA: Head and neck squamous cell carcinoma: Update on epidemiology, diagnosis, and treatment. Mayo Clin Proc 91: 386-936, 2016.

4. Farshadpour F, Kranenborg H, Calkoen EV, Hordijk GJ, Koole R, Slootweg PJ and Terhaard CH: Survival analysis of head and neck squamous cell carcinoma: Influence of smoking and drinking. Head Neck 33: 817-823, 2011.

5. Stucken CL, de Almeida JR, Sikora AG, Tong CC and Genden EM: Impact of human papillomavirus and smoking on survival outcomes after transoral robotic surgery. Head Neck 38: 380-386, 2016.

6. Lassig AA, Yueh B and Joseph AM: The effect of smoking on perioperative complications in head and neck oncologic surgery. Laryngoscope 122: 1800-1808, 2012.

7. Chen AM, Chen LM, Vaughan A, Farwell DG, Luu Q, Purdy JA and Vijayakumar S: Head and neck cancer among lifelong never-smokers and ever-smokers: Matched-pair analysis of outcomes after radiation therapy. Am J Clin Oncol 34: 270-275, 2011.

8. Choi SH, Terrell JE, Bradford CR, Ghanem T, Spector ME, Wolf GT, Lipkus IM and Duffy SA: Does quitting smoking make a difference among newly diagnosed head and neck cancer patients? Nicotine Tob Res 18: 2216-2224, 2016.

9. Sharp L, McDevitt J, Carsin AE, Brown C and Comber H: Smoking at diagnosis is an independent prognostic factor for cancer-specific survival in head and neck cancer: Findings from a large, population-based study. Cancer Epidemiol Biomarkers Prev 23: 2579-2590, 2014. 
10. Browman GP, Wong G, Hodson I, Sathya J, Russell R, McAlpine L, Skingley $\mathrm{P}$ and Levine MN: Influence of cigarette smoking on the efficacy of radiation therapy in head and neck cancer. N Engl J Med 328: 159-163, 1993.

11. Fountzilas G, Kosmidis P, Avramidis V, Nikolaou A, Kalogera-Fountzila A, Makrantonakis P, Bacoyiannis C, Samantas E, Skarlos D and Daniilidis J: Long-term survival data and prognostic factors of a complete response to chemotherapy in patients with head and neck cancer treated with platinum-based induction chemotherapy: A Hellenic Co-operative oncology group study. Med Pediatr Oncol 28: 401-410, 1997.

12. Grønkjær M, Eliasen M, Skov-Ettrup LS, Tolstrup JS, Christiansen AH, Mikkelsen SS, Becker U and FlensborgMadsen T: Preoperative smoking status and postoperative complications: A systematic review and meta-analysis. Ann Surg 259: 52-71, 2014.

13. Wandt H, Schäfer-Eckart K and Greinacher A: Platelet transfusion in hematology, oncology and surgery. Dtsch Arztebl Int 111: 809-815, 2014.

14. Gillison ML, Zhang Q, Jordan R, Xiao W, Westra WH, Trotti A, Spencer S, Harris J, Chung CH and Ang KK: Tobacco smoking and increased risk of death and progression for patients with p16-positive and p16-negative oropharyngeal cancer. J Clin Oncol 30: 2102-2111, 2012 .

15. Hong AM, Martin A, Chatfield M, Jones D, Zhang M, Armstrong B, Lee CS, Harnett G, Milross C, Clark J, et al: Human papillomavirus, smoking status and outcomes in tonsillar squamous cell carcinoma. Int J Cancer 132: 2748-2754, 2013.

16. Beynon RA, Lang S, Schimansky S, Penfold CM, Waylen A, Thomas SJ, Pawlita M, Waterboer T, Martin RM, May M and Ness AR: Tobacco smoking and alcohol drinking at diagnosis of head and neck cancer and all-cause mortality: Results from head and neck 5000, a prospective observational cohort of people with head and neck cancer. Int J Cancer 143: 1114-1127, 2018.
17. Peterson LA, Bellile EL, Wolf GT, Virani S, Shuman AG, Taylor JM and Rozek LS; University of Michigan Head and Neck Specialized Program of Research Excellence Program: Cigarette use, comorbidities, and prognosis in a prospective head and neck squamous cell carcinoma population. Head Neck 38: 1810-1820, 2016.

18. Dumanski JP, Rasi C, Lönn M, Davies H, Ingelsson M, Giedraitis V, Lannfelt L, Magnusson PK, Lindgren CM, Morris AP, et al: Mutagenesis. Smoking is associated with mosaic loss of chromosome Y. Sience 347: 81-83, 2015.

19. Kawakita D, Hosono S, Ito H, Oze I, Watanabe M, Hanai N, Haseqawa Y, Tajima H, Murakami S, Tanaka $\mathrm{H}$ and Matsuo K: Impact of smoking status on clinical outcome in oral cavity cancer patients. Oral Oncol 48: 186-191, 2012.

20. Sethi S, Ali-Fehmi R, Franceschi S, Struijk L, van Doorn LJ, Quint W, Albashiti B, Ibrahim M and Kato I: Characteristics and survival of head and neck cancer by HPV status: A cancer registry-based study. Int J Cancer 131: 1179-1186, 2012.

21. Browman GP, Mohide EA, Willan A, Hodson I, Wong G, Grimard L, MacKenzie RG, El-Sayed S, Dunn E and Farrell S: Association between smoking during radiotherapy and prognosis in head and neck cancer: A follow-up study. Head Neck 24: 1031-1037, 2002.

(7) $(2)$ This work is licensed under a Creative Commons Attribution-NonCommercial-NoDerivatives 4.0 International (CC BY-NC-ND 4.0) License. 